\title{
Validation of an analytical method for the determination in serum of psychotropic drugs by High-Performance Liquid Chromatography with Diode Array Detection
}

\author{
Innocent Hahirwa ${ }^{1,2 *}$, Corinne Charlier ${ }^{1}$, Charles Karangwa ${ }^{2}$, Raphaël Denooz ${ }^{1}$ \\ ${ }^{1}$ Laboratory of Clinical, Forensic, Environmental and Industrial Toxicology, CHU-Liege, 4000 Liege, Belgium \\ ${ }^{2}$ Laboratory of Analysis of Foodstuffs, Drugs, Water and Toxics, University of Rwanda, School of Medicine and Pharmacy, 117 \\ Huye, Rwanda
}

\begin{abstract}
Background: Inter-individual variability in clinical response to psychotropic drugs remains problematic in management of mental illnesses. The patients differ in their ability to absorb, distribute, metabolize and eliminate drugs due to genetic peculiarities, concurrent disease, age, or concomitant medication Methods: A simple and sensitive high performance liquid chromatography method with ultraviolet detection was validated for the determination of 27 psychotropic drugs in serum. The analysis by High-Performance Liquid Chromatography (HPLC) was performed on serum spiked with analyte(s), and prazepam was used as an internal standard. To get validation parameters, analytical results were processed based upon the total error concept using Enoval software. Results: The validated method was linear over the tested dosing intervals with a coefficient of determination of at least 0.99 for all molecules. The relative standard deviation (\%-RSD) and bias were less than $15 \%$ for all validation standards and the recovery varied between $92.7 \%$ and $112.9 \%$. The accuracy of the method was demonstrated over the used dosing intervals. Conclusion: The method is suitable for both therapeutic drug monitoring and confirmation of drug poisoning, except for haloperidol, flupentixol and zuclopenthixol where it is only applicable for the confirmation of intoxication.
\end{abstract}

Key words: Psychotropic drugs, serum, validation, HPLC-DAD

\section{Introduction}

The inter-individual variability in clinical response to psychotropic drugs remains problematic in the management of mental illnesses (Malhotra, Murphy \& Kennedy, 2004; Vecchione et al., 2012). The eventual toxicity of these drugs, especially barbiturates, antipsychotics and antidepressants can worsen the patient status and may be due to a poorly adapted dosing. Furthermore, due to the widespread use of these drugs, cases of deliberate and accidental poisoning with these drugs have become a major medical problem (Sanchez, Martinez \& Almarza, 2005; Smink et al. 2004).

During the last 60 years, around 130 drugs have been developed in psychiatry. Despite enormous medical and economic benefits of the drugs, for many patients therapeutic outcomes are still far from satisfactory (Addington, 2009; Adli, Baethge, Heinz, Langlitz \& Bauer, 2005; Jeffrey at al., 2005; Trivedi et al., 2007). Instead of continuing to focus on the development of new drugs, as it has been the case for more than 5 decades, there is growing evidence suggesting that substantial benefit to patients may be brought by improving the way the available medications are administered (Bates \& Gawande, 2003; Hiemke et al. 2011). In psychotropic therapy, it has been demonstrated that incidence of undesirable effects is often dose-related and for some psychotropic drugs, the same correlation has been observed for therapeutic effects and plasma levels (Raggi, 2002; Bengtsson, 2004) To tailor the dosage of the prescribed medication(s) to the individual characteristics of a patient, therapeutic drug monitoring (TDM) is a valuable tool. Patients differ in their ability to absorb, distribute, metabolize and eliminate drugs due to genetic peculiarities, concurrent disease, age, or concomitant medication. At the very same dose a more than 20 -fold inter-individual variation in the medication's steady state concentration in the body can be observed (Raggi, 2002; Brosen, 1996; Hiemke, 2008a; Hiemke, 2008b, Klotz, 2009). The use of TDM helps to determine the dose of individual patients in order to obtain an optimal drug concentration. Moreover, TDM has also a potential to improve psychopharmacotherapy cost-effectiveness (Preskorn \& Fast, 1991; Touw, Neef, Thomson \& Vinks., 2005). To adjust dose for a considerable number of psychotropic drugs, the determination of their plasma levels has become a clinical routine. For a large number of these drugs including tricyclic antidepressants, antipsychotic drugs and conventional mood stabilizing drugs clear evidence of benefits of TDM has been exhibited (Baumann et al.,

*Corresponding author: ihahirwa@student.ulg.ac.be, i.hahirwa@ur.ac.rw 
2004; Müller et al., 2004). To disclose abnormal levels in patients with atypical metabolic rates or in forensic practice measurements of serum concentrations of psychotropic drugs and their metabolites may also be useful (Cutroneo, Beljean, Tan Luu \& Siouffi, 2006; Sheng, Lei, Ju, Song \& Zhang, 2010).

So far, several techniques based on liquid chromatography (Bugamelli et al., 2002), spectrophotometry, immunoassay (Zhang, Heineman \& Halsall, 1999), electrochemistry (Wilhelm, Battista \& Obendorf, 2000), gas chromatography and electrophoresis (Wang, Fan, Zhang \& Cao, 2006) have been proposed for the determination of psychotropic drugs in biological fluids. Since most of these drugs are thermally labile and water soluble, reversed-phase liquid chromatography has interesting features in routine TDM (Cutroneo et al., 2006; Sheng et al., 2010). This technique can thus be used to carry out TDM of psychotropic drugs in Rwanda and therefore optimize treatment with these drugs.

Psychotropic drugs are used in Rwanda to treat usual mental illnesses but also to manage some of the psychological problems directly related to the genocide against Tutsi.. So far in Rwanda, to the best of our knowledge, no control of plasma concentration levels is done to optimize the treatment with these drugs and reduce the risk of toxicity to patients.

This prompted us to undertake a study aiming to develop and validate an HPLC-DAD technique that can be used to determine in serum psychotropic drugs most commonly used in Rwanda. To identify the concerned drugs, a survey on of psychotropic drug use in Rwanda has been conducted in various hospitals and institutions involved in management of psychotropic drugs in Rwanda. Visited sites were: Butare University Teaching Hospital (CHUB), Kigali University teaching Hospital (CHUK), King Faisal Hospital (KFH), Rwanda Military Hospital, Ndera Neuropsychiatric Hospital (HNPN), the Pharmacy Task Force in the Ministry of Health (PTF$\mathrm{MoH})$, the Psychosocial Consultation Service-CHUK (SCPS-CHUK), and Rwanda Biomedical Center-Medical Procurement (RBC-MP).

Based upon the results of this survey, the following drugs have been selected for the present study: alprazolam, amitriptyline, bromazepam, carbamazepine, chlorpromazine, citalopram, clomipramine, clonazepam, diazepam, droperidol, fluoxetine, flupentixol, haloperidol, imipramine, levomepromazine, lorazepam, midazolam, nordiazepam, olanzapine, phenobarbital, phenytoin, pipamperone, risperidone, sulpiride, thiopental, zolpidem and zuclopenthixol.

For an analytical method to be used in routine activities, analytical validation process is compulsory. This process aims to appreciate the performance of the method and evaluate it by experimentation if the method meets the expected requirements. Response function, linearity, limits of quantification and detection, selectivity, trueness, precision and accuracy are validation parameters commonly tested during the validation process (Rozet et al., 2007; Hubert et al., 2007a).

\section{Methods}

\section{Chemicals and reagents}

Compounds used as reference standards were purchased from various suppliers. Alprazolam and lorazepam have been obtained from Pfizer (Brussels, Belgium); amitriptyline, carbamazepine, clomipramine, and imipramine from LGC GmbH (Luckenwalde, Germany); bromazepam, clonazepam, and midazolam from Roche (Brussels, Belgium); citalopram, flupentixol, and zuclopenthixol from Lundbeck (Brussels, Belgium); chlorpromazine, diazepam, fluoxetine, nordiazepam, olanzapine, phenobarbital and zolpidem from Cerilliant (Texas, USA); droperidol from Prostrakan (Saint Claude, France); haloperidol, pipamperone, and risperidone from Jassen-Cilag (Antwerp, Belgium); levomepromazine and sulpiride from Sanofi-Aventis (Diegen, Belgium); phenytoin from Kela Pharma (Sint Niklaas, Belgium) and thiopental from Inresa (Freiburg, Germany). Prazepam was purchased from Certa (Braine-l'Alleud, Belgium). Sodium carbonate and sodium dihydrogenophosphate were respectively purchased from Merck (Darmastadt, Germany) and J.T. Baker (Deventer, the Netherlands). Acetonitrile was purchased from Lab Scan (Dublin, Ireland); n-Amyl alcohol and dichloromethane from J.T. Baker (Deventer, the Netherlands); n-hexane and methanol from Lab Scan (Sowinskeigo, Poland)and diethyl ether and acetonitrile supra gradient from Biosolve (Valkenswaard, the Netherlands). All organic solvents were certified for HPLC use. Blank human serum was obtained from CHU Liege blood bank.

\section{Chromatographic conditions}

The used chromatographic system consisted of a Waters Alliance 2695 Separations Module (Zellik, Belgium), equipped with a quaternary, low-pressure mixing pump, a degassing line and a thermostated autosampler and coupled to a 2996 photodiode array detector. The HPLC instrument was piloted by Empower ${ }^{\mathbb{B}}$ software (Waters) which was used also for data processing (area integration, calculation and plotting of chromatograms). Baselines were visually inspected with manual adjustment whenever necessary. A Symmetry ${ }^{\circledR} \mathrm{C} 8$ analytical column $(4.6 \mathrm{~mm} \times 250 \mathrm{~mm})$ packed with $5 \mu \mathrm{m}$ diameter particles (Waters), together with a guard column $(20 \mathrm{~mm} \times 4.6 \mathrm{~mm})$ 
packed with identical material were used for separation performed at $30^{\circ} \mathrm{C}$. An injection volume of $40 \mu \mathrm{L}$, a carousel temperature of $25^{\circ} \mathrm{C}$ and a run time of $45 \mathrm{~min}$ were fixed. The mobile phase consisted of acetonitrile (A) and sodium dihydrogenophosphate buffer (B) used in gradient elution mode: the run started with $13 \%$ (A) which was increased to $35 \%$ in 9 min and $80 \%$ in 28 min. This proportion was maintained for $2 \mathrm{~min}$ before decreasing and turning back to starting conditions held till the end of the run. The flow varied between 1 and 1.5 $\mathrm{mL} / \mathrm{min}$. UV-visible spectra were recorded in the range 200-400 nm.

\section{Solutions}

Standard stock solutions were obtained either immediately from suppliers or prepared by dissolving various compounds in methanol. The same solvent was also used whenever dilution was necessary. Stock solutions were refrigerated between 2 and $8^{\circ} \mathrm{C}$. Calibration and validation standard samples were prepared by spiking blank serum with an adequate amount of standard stock solutions. Sodium carbonate solution used in extraction was prepared by dissolving $21.2 \mathrm{~g}$ of $\mathrm{Na}_{2} \mathrm{CO}_{3}$ into $200 \mathrm{~mL}$ of bidistilled water. Phosphate buffer solution was obtained by dissolving $6.0 \mathrm{~g}$ of sodium dihydrogenophosphate into $1000 \mathrm{~mL}$ of bidistilled water and the $\mathrm{pH}$ was adjusted to 3.8 using phosphoric acid. The filtration prior to use was compulsory for the buffer solution.

\section{Sample preparation}

One milliliter of serum sample was needed for the analysis and $100 \mu \mathrm{L}$ of prazepam $10 \mathrm{mg} / \mathrm{L}$ (internal standard) were added to the sample prior to extraction. To make the extraction more efficient, $500 \mu \mathrm{L}$ of sodium carbonate were used to increase the sample ionic strength and thus decrease the water solubility of our analytes (organic compounds) and facilitate their transfer to the organic phase. The extraction was performed using $5 \mathrm{~mL}$ of a mix of organic solvents: diethyl ether/dichloromethane/ hexane/n-amyl alcohol (50/30/20/0.5: V/V/V/V). After shaking during $10 \mathrm{~min}$ and centrifuging during $10 \mathrm{~min}$ at 2000 rounds/min, $3.5 \mathrm{~mL}$ of the supernatant were picked up and evaporated to dryness under the nitrogen at $40^{\circ} \mathrm{C}$ maximum. Seventy microliters of a mix of acetonitrile and bidistilled water were used in a 50/50 ratio for recovery. After a 5 min centrifugation into Eppendorf tube, the supernatant was put into a vial for HPLC analysis.

\section{Method of validation}

\section{Validation parameters assessed}

\section{Response function}

The response function of an analytical procedure stands for the relationship existing, within a specified range, between the response (signal) and the concentration (quantity) of analyte in the sample (Rozet et al., 2007; Hubert et al., 2007a).

\section{Selectivity}

The selectivity of an analytical method refers to the extent to which the method can determine the particular analyte (s) in a complex mixture without interference from other components of the mixture. In other words this parameter refers to the ability of the method to discriminate between the analytes and interfering compounds (Rozet et al., 2007; Hubert et al., 2007a).

\section{Linearity}

The linearity of an analytical procedure refers to the relationship between introduced quantity (concentration) and the concentration back-calculated from the calibration curve. This criterion shows the ability of the method within a specified range, to obtain results directly proportional to concentrations of analyte in samples (Rozet et al., 2007; Hubert et al., 2007a).

\section{Trueness}

The trueness stands for the closeness of agreement between conventionally accepted value or reference value and the average value obtained from a large series of tested results. The trueness usually expressed in terms of bias, relative bias or recovery gives information on systematic error (Rozet et al., 2007).

\section{Precision}

According to various regulatory documents, the precision of an analytical procedure is defined as closeness of agreement between series of measurements obtained from multiple sampling of the same homogeneous sample under prescribed conditions. This validation parameter provides information on random errors. Standard deviation, relative standard deviation (RSD \%) or coefficient of variation (CV) are used to express the precision (Hubert et al., 2007a).

\section{Accuracy}

The accuracy of an analytical method refers to the closeness of agreement between the test result and the value accepted either as the reference value or conventional true value. Actually, this closeness of agreement results from the total error related to test result, i.e. random and systematic errors. Therefore, the accuracy expresses the sum of precision and trueness of an analytical procedure 
(Rozet et al., 2007; Kratzsch, Peters, Kraemer, Weber \& Maurer, 2002).

\section{Limits of detection and quantification}

The limit of detection of an analytical procedure is the lowest amount of analyte in a sample that can be detected. Low and upper limits of quantification (LLOQ and ULOQ) are respectively the lowest quantity and the highest quantity of analyte in the sample that can accurately be quantitatively determined. Among other approaches used to determine the LOD and LLOQ there is the signal-to-noise $(\mathrm{S} / \mathrm{N})$ ratio approach. According to the International Conference on the Harmonization, the $\mathrm{S} / \mathrm{N}$ ratios of 3:1 and 10:1 are considered respectively for the LOD and LLOQ (Rozet et al., 2007).

\section{Validation process}

Validation process was carried out according to the general guidelines for validation of analytical methods (Rozet et al., 2007; Hubert et al., 2007a).
Calibration standard samples were prepared in duplicates for three consecutive days at six levels of concentration within a range covering molecule therapeutic windows to evaluate the response function relationship of the method. Calibration curves were obtained by plotting ratios of analyte peak area over internal standard peak area versus the analyte concentrations in spiked samples.

In line with the above mentioned guidelines, three levels of concentration covering therapeutic windows (Table 1) for various molecules have been prepared in triplicates on three consecutive days to demonstrate the linearity, precision, trueness, measurement uncertainty and accuracy of the method. Results were processed according to the total error concept with the Enoval V3.0 software (Arlenda, 2011).

The limits of detection (LOD) and quantification (LOQ) were defined as the lowest concentrations of analyte in a sample that can be detected and quantified. The LOD and LOQ were determined on the basis of signal-tonoise ratios $(\mathrm{S} / \mathrm{N})$ of $3: 1$ and 10:1 respectively (Rozet et al., 2007).

Table 1. Concentration ranges used in preparation of calibration and validation standards

\begin{tabular}{|c|c|c|c|}
\hline Drugs & $\begin{array}{l}\text { Reference values } \\
(\mathrm{ng} / \mathrm{mL})\end{array}$ & $\begin{array}{l}\text { Calibration Standards } \\
(\mathrm{ng} / \mathrm{mL})\end{array}$ & $\begin{array}{l}\text { Validation standards } \\
(\mathrm{ng} / \mathrm{mL})\end{array}$ \\
\hline Alprazolam & $10-50$ & $10-400$ & $40-300$ \\
\hline Amitriptyline & $50-200$ & $20-800$ & $60-600$ \\
\hline Bromazepam & $80-170$ & $50-2000$ & $150-1250$ \\
\hline Carbamazepine & $6000-12000$ & $1000-50000$ & $2500-50000$ \\
\hline Chlorpromazine & $30-300$ & $20-1000$ & $80-800$ \\
\hline Citalopram & $20-200$ & $20-1000$ & $50-1000$ \\
\hline Clomipramine & $100-250$ & $50-1200$ & $120-1000$ \\
\hline Clonazepam & $20-80$ & $10-500$ & $40-400$ \\
\hline Diazepam & $125-1500$ & $100-4000$ & $400-3000$ \\
\hline Droperidol & $5-50$ & $25-600$ & $60-500$ \\
\hline Fluoxetine & $100-450$ & $50-2000$ & $150-1500$ \\
\hline Flupentixol & $1-15$ & $10-500$ & $25-500$ \\
\hline Haloperidol & $5-17$ & $5-200$ & $15-150$ \\
\hline Imipramine & $45-250$ & $20-800$ & $60-600$ \\
\hline Levomepromazine & $15-60$ & $10-500$ & $40-400$ \\
\hline Lorazepam & $20-250$ & $20-1000$ & $80-800$ \\
\hline Midazolam & $80-250$ & $50-2000$ & $200-1500$ \\
\hline Nordiazepam & $200-1800$ & $100-4000$ & $300-2500$ \\
\hline Olanzapine & $20-80$ & $10-400$ & $30-300$ \\
\hline Phenobarbital & $15000-40000$ & $5000-200000$ & $15000-150000$ \\
\hline Phenytoin & $10000-20000$ & $2000-80000$ & $6000-50000$ \\
\hline Pipamperone & $100-400$ & $100-4000$ & $400-3000$ \\
\hline Risperidone & $20-60$ & $10-500$ & $40-400$ \\
\hline Sulpiride & $200-1000$ & $100-5000$ & $400-4000$ \\
\hline Thiopental & $1000-5000$ & $500-20000$ & $1500-12500$ \\
\hline Zolpidem & $80-300$ & $50-2000$ & $150-1250$ \\
\hline Zuclopenthixol & $4-50$ & $10-500$ & $25-500$ \\
\hline
\end{tabular}

Reference values stand for therapeutic windows of various molecules, calibration standards are points (prepared concentration levels) of calibration curves, while validation standards stand for concentration levels used to determine various validation parameters. 


\section{Results}

\section{Response function}

Calibration standards prepared in duplicates at six levels of concentration (Table 1) on three consecutive days were used to assess this criterion. A linear response function was obtained and generated calibration curves had at least 0.99 as coefficient of determination $\left(\mathrm{R}^{2}\right)$. These curves were used to determine analyte concentrations in validation standards.
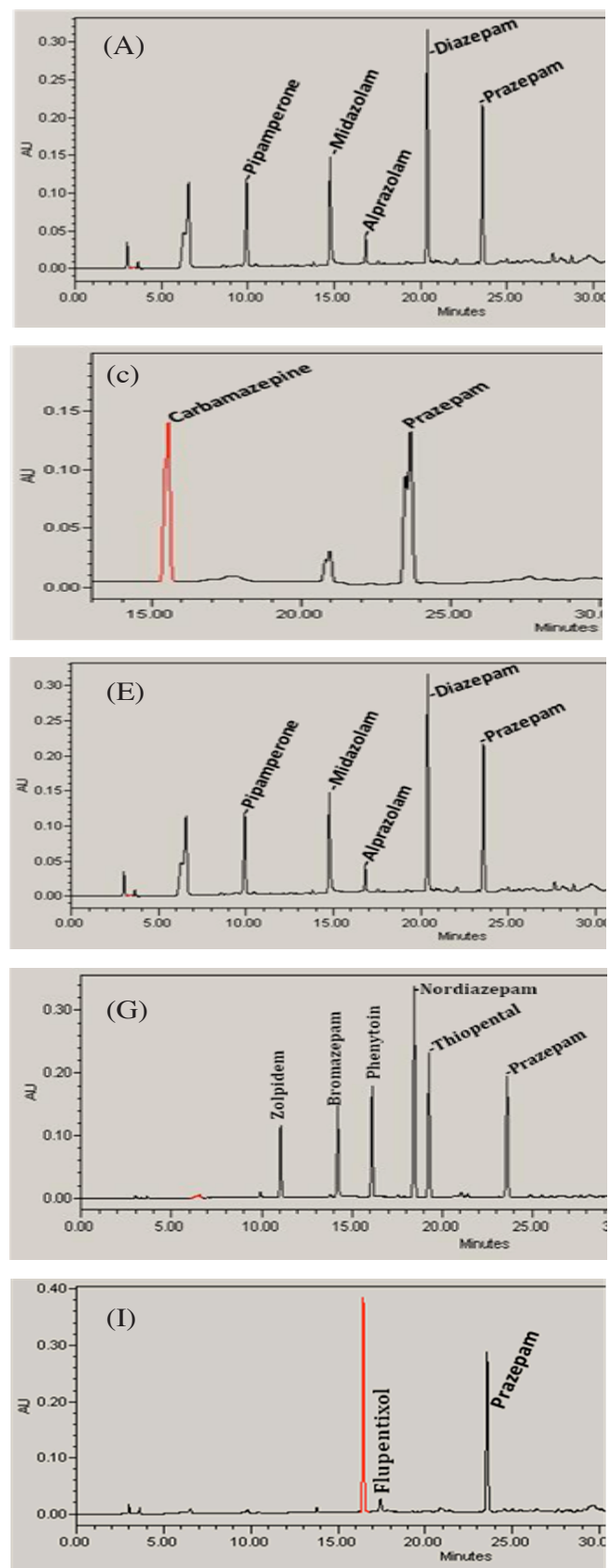

\section{Selectivity}

Retention times and UV spectra (Fig. 2) were parameters used to assess the selectivity of detection of the method. As exhibited by the chromatograms (Fig. 1), the method allows simultaneous separation of several molecules and peaks with good resolution were obtained. However, a simulations separation of molecules with relatively same retention times was not easy to get and this was the case for carbamazepine, imipramine and levomepromazine; alprazolam and lorazepam; chlorpromazine, fluoxetine and zuclopenthixol; clonazepam and flupentixol.
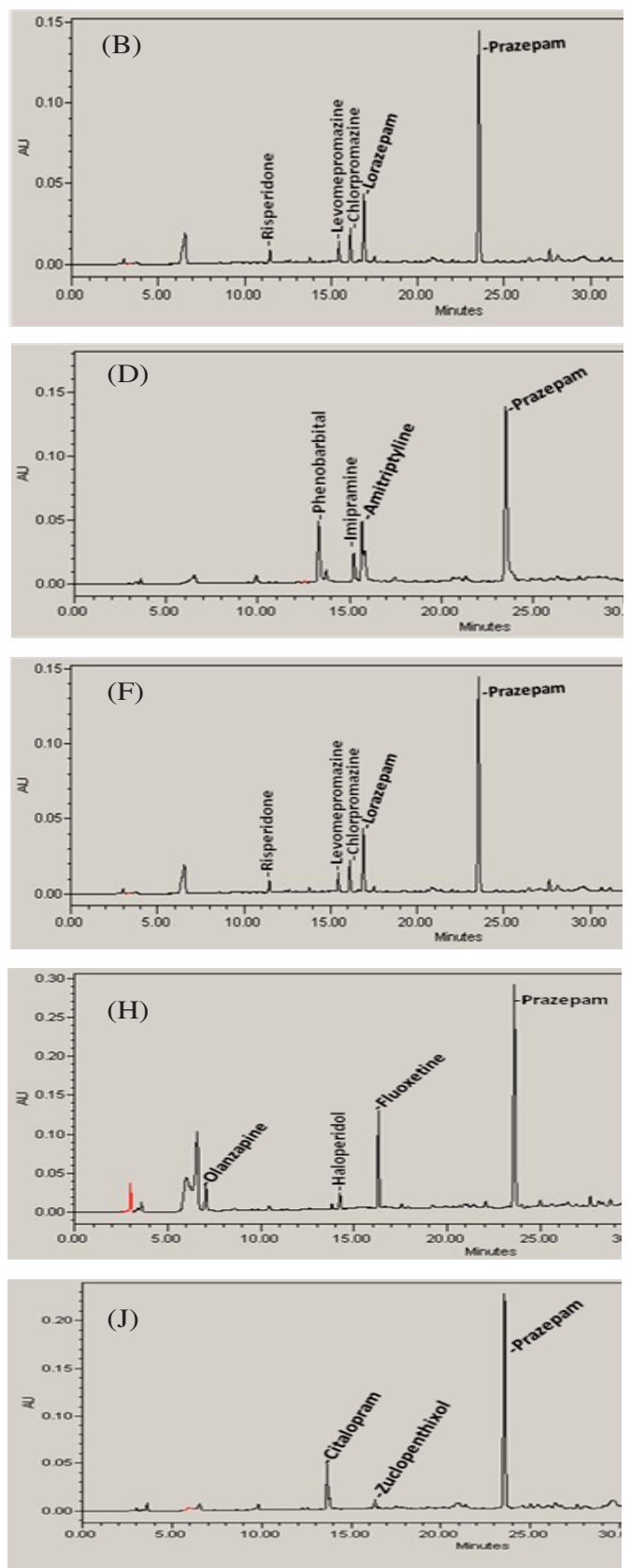

Figure 1. HPLC chromatograms for various molecules 
Figure 1 shows HPLC chromatograms obtained with serum containing droperidol $150 \mathrm{ng} / \mathrm{mL}$, clomipramine $300 \mathrm{ng} / \mathrm{mL}$, thiopental $5000 \mathrm{ng} / \mathrm{mL}$ (A), sulpiride 1000 $\mathrm{ng} / \mathrm{mL}$, phenytoin $20000 \mathrm{ng} / \mathrm{mL}$, clonazepam $100 \mathrm{ng} /$ $\mathrm{mL}$ (B), carbamazepine $10000 \mathrm{ng} / \mathrm{mL}$ (C), phenobarbital $50000 \mathrm{ng} / \mathrm{mL}$, imipramine $200 \mathrm{ng} / \mathrm{mL}$, amitriptyline $200 \mathrm{ng} / \mathrm{mL}$ (D), pipamperone $1000 \mathrm{ng} / \mathrm{mL}$, midazolam $500 \mathrm{ng} / \mathrm{mL}$, alprazolam $100 \mathrm{ng} / \mathrm{mL}$, diazepam $1000 \mathrm{ng} /$
$\mathrm{mL}$ (E), risperidone $100 \mathrm{ng} / \mathrm{mL}$, levomepromazine 100 $\mathrm{ng} / \mathrm{mL}$, chlorpromazine $200 \mathrm{ng} / \mathrm{mL}$, lorazepam 200 $\mathrm{ng} / \mathrm{mL}$ (F), zolpidem $500 \mathrm{ng} / \mathrm{mL}$, bromazepam 500 $\mathrm{ng} / \mathrm{mL}$, phenytoin $20 \mathrm{ng} / \mathrm{mL}$, nordizepam $1000 \mathrm{ng} /$ $\mathrm{mL}$, thiopental $5000 \mathrm{ng} / \mathrm{mL}(\mathrm{G})$, olanzapine $100 \mathrm{ng} /$ $\mathrm{mL}$, haloperidol $50 \mathrm{ng} / \mathrm{mL}$, fluoxetine $500 \mathrm{ng} / \mathrm{mL}(\mathrm{H})$, flupentixol $100 \mathrm{ng} / \mathrm{mL}$ (I), citalopram $200 \mathrm{ng} / \mathrm{mL}$, and Zuclopenthixol $100 \mathrm{ng} / \mathrm{mL}(\mathrm{J})$

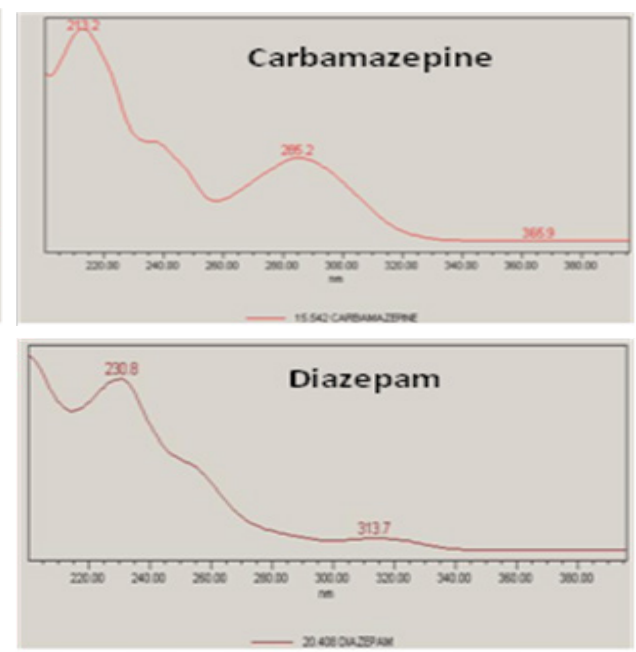

Figure 2. UV-visible spectra of 4 molecules taken as examples between 200 and $400 \mathrm{~nm}$

UV-visible spectra of analytes in the sample were compared to those registered in the library of the method to confirm the real presence of the analyte. A wavelength of maximum absorbance was automatically selected for each molecule (Figure 2).

\section{Linearity}

The validated analytical procedure showed a good linearity within tested dosing intervals (Table 1) with determination coefficients of not less than 0.99 for all molecules, i.e. it allowed us to obtain results directly proportional to concentrations of analyte in analyzed samples.

\section{Trueness}

The trueness parameter was assessed by calculating the relative bias and the recovery. Calculations were performed using Enoval software and the results are presented in table 2. For all tested drugs the results for relative bias were systematically inferior to $15 \%$.

\section{Precision}

Both intra-assay (repeatability) and inter-assay (intermediate precision) have been assessed during the validation process and obtained results for the relative standard deviation (RSD) are presented in table 2 . Thirteen percent was the maximum value for the RSD when we consider both repeatability and intermediate precision.

\section{Accuracy}

To assess this validation parameter for the present analytical method, an accuracy profile generated by Enoval software has been used. We set acceptance limits at $\pm 30 \%$ and the risk of having future measurements outside acceptance limits has been set at $17.5 \%$. Figure 3 presents accuracy profiles obtained for various molecules.

\section{Limits of detection and quantification}

On one side the signal to noise $(\mathrm{S} / \mathrm{N})$ approach was used to determine the LOD and LLOQ and the $\mathrm{S} / \mathrm{N}$ ratios of 3:1 and 10:1 were considered respectively for the LOD and LLOQ. On the other side, the intersection of the accuracy profile and acceptance limits was considered to determine the upper limits of quantification of the method. Results for both LOD and LOQ are presented in Table 3. 
Table 2. Precision and trueness assessment

\begin{tabular}{|c|c|c|c|c|c|c|c|c|c|c|c|}
\hline \multirow{2}{*}{ Analytes } & \multirow{2}{*}{$\begin{array}{c}\text { Nominal } \\
{[]} \\
(\mathrm{ng} / \mathrm{mL})\end{array}$} & \multicolumn{2}{|c|}{$\mathbf{A}$} & \multicolumn{2}{|c|}{ B } & \multirow{2}{*}{ Analytes } & \multirow{2}{*}{$\begin{array}{c}\text { Nominal } \\
{[]} \\
(\mathrm{ng} / \mathrm{mL})\end{array}$} & \multicolumn{2}{|c|}{$\mathbf{A}$} & \multicolumn{2}{|c|}{ B } \\
\hline & & A1 & A2 & B1 & B2 & & & A1 & A2 & B1 & B2 \\
\hline \multirow{3}{*}{ Alprazolam } & 40.00 & 8.25 & 10.81 & 2.50 & 102.50 & \multirow{3}{*}{$\begin{array}{l}\text { Levomeproma- } \\
\text { zine }\end{array}$} & 40.0 & 5.32 & 10.47 & 4.73 & 104.70 \\
\hline & 150.0 & 4.30 & 7.99 & -0.96 & 99.04 & & 150.0 & 3.51 & 8.50 & 4.59 & 104.60 \\
\hline & 300.0 & 3.67 & 6.87 & -4.44 & 95.56 & & 400.0 & 1.49 & 7.51 & 7.33 & 107.30 \\
\hline \multirow{3}{*}{ Amitriptyline } & 60.00 & 3.00 & 4.05 & 4.02 & 104.00 & \multirow{3}{*}{ Lorazepam } & 80.00 & 2.98 & 6.90 & -0.6 & 99.44 \\
\hline & 300.0 & 3.17 & 4.08 & 6.94 & 106.90 & & 300.0 & 2.52 & 8.13 & -0.30 & 99.70 \\
\hline & 600.0 & 2.00 & 2.37 & 4.06 & 104.10 & & 800.0 & 3.88 & 6.90 & 0.06 & 100.10 \\
\hline \multirow{3}{*}{ Bromazepam } & 150.0 & 0.92 & 2.83 & -3.78 & 96.22 & \multirow{3}{*}{ Midazolam } & 200.0 & 3.08 & 5.86 & -3.06 & 96.94 \\
\hline & 375.0 & 1.21 & 2.26 & -1.51 & 98.49 & & 750.0 & 3.28 & 6.95 & -3.57 & 96.43 \\
\hline & 1250 & 1.08 & 2.27 & -1.18 & 98.82 & & 1500 & 3.90 & 5.55 & -3.06 & 96.94 \\
\hline \multirow{3}{*}{$\begin{array}{l}\text { Carbamaze- } \\
\text { pine }\end{array}$} & 2500 & 1.95 & 5.16 & 0.58 & 100.60 & \multirow{3}{*}{ Nordiazepam } & 300.0 & 0.52 & 3.97 & -1.30 & 98.70 \\
\hline & 20000 & 3.50 & 4.70 & 0.20 & 100.20 & & 750.0 & 1.32 & 2.74 & -0.07 & 99.93 \\
\hline & 50000 & 1.14 & 4.38 & 0.44 & 100.40 & & 2500 & 0.65 & 2.32 & -1.60 & 98.40 \\
\hline \multirow{3}{*}{$\begin{array}{l}\text { Chlorproma- } \\
\text { zine }\end{array}$} & 80.00 & 1.15 & 1.72 & 0.53 & 100.50 & \multirow{3}{*}{ Olanzapine } & 30.00 & 9.75 & 10.27 & -7.27 & 92.73 \\
\hline & 300.0 & 2.65 & 6.68 & 6.56 & 106.60 & & 80.00 & 6.10 & 13.21 & -1.05 & 98.95 \\
\hline & 800.0 & 2.60 & 4.19 & 4.66 & 104.70 & & 300.0 & 9.52 & 9.52 & -4.20 & 95.80 \\
\hline \multirow{3}{*}{ Citalopram } & 50.00 & 2.36 & 3.06 & -0.81 & 99.19 & \multirow{3}{*}{ Phenobarbital } & 15000 & 5.83 & 7.43 & 2.30 & 102.30 \\
\hline & 400.0 & 1.94 & 4.81 & 6.45 & 106.50 & & 75000 & 3.26 & 3.57 & 0.73 & 100.70 \\
\hline & 1000 & 0.85 & 1.65 & 1.47 & 101.50 & & 150000 & 3.54 & 5.12 & 1.27 & 101.30 \\
\hline \multirow{3}{*}{ Clomipramine } & 120.0 & 2.64 & 3.44 & 12.90 & 112.90 & & 6000 & 2.51 & 6.72 & 11.06 & 111.10 \\
\hline & 400.0 & 3.48 & 5.28 & 3.53 & 103.50 & Phenytoin & 15000 & 1.81 & 4.52 & 12.84 & 112.80 \\
\hline & 1000 & 3.38 & 7.66 & -0.54 & 99.46 & & 50000 & 2.27 & 4.49 & 6.16 & 106.20 \\
\hline & 40.00 & 2.36 & 6.14 & -1.67 & 98.33 & & 400.0 & 3.77 & 6.98 & -0.81 & 99.19 \\
\hline Clonazepam & 150.0 & 6.42 & 7.40 & -3.26 & 96.74 & Pipamperone & 1500 & 5.13 & 9.05 & -2.79 & 97.21 \\
\hline & 400.0 & 5.73 & 7.86 & -0.44 & 99.56 & & 3000 & 4.27 & 8.62 & -3.79 & 96.21 \\
\hline & 400.0 & 4.76 & 7.20 & 0.92 & 100.90 & & 40.00 & 4.35 & 4.35 & 3.58 & 103.60 \\
\hline Diazepam & 1500 & 4.96 & 8.76 & -2.16 & 97.84 & Risperidone & 150.0 & 5.20 & 8.77 & 9.27 & 109.30 \\
\hline & 3000 & 4.63 & 7.37 & -4.03 & 95.97 & & 400.0 & 3.90 & 7.13 & 7.57 & 107.60 \\
\hline & 60.00 & 3.35 & 4.49 & 2.94 & 102.90 & & 400 & 3.16 & 3.83 & 5.25 & 105.30 \\
\hline Droperidol & 200.0 & 4.25 & 5.52 & 5.05 & 105.10 & Sulpiride & 1500 & 2.58 & 2.85 & -1.18 & 98.82 \\
\hline & 500.0 & 1.54 & 4.95 & 5.52 & 105.50 & & 4000 & 2.99 & 2.99 & 0.10 & 100.10 \\
\hline & 150.0 & 4.76 & 6.89 & -2.63 & 97.37 & & 1.500 & 1.63 & 3.30 & -3.26 & 96.74 \\
\hline Fluoxetine & 400.0 & 1.79 & 6.11 & 6.67 & 106.70 & Thiopental & 3.750 & 1.28 & 2.67 & -1.63 & 98.37 \\
\hline & 1500 & 5.44 & 7.30 & 5.90 & 105.90 & & 12.50 & 1.92 & 3.66 & -2.21 & 97.79 \\
\hline & 25.00 & 3.15 & 4.18 & 3.84 & 103.80 & & 150.0 & 0.63 & 3.59 & -2.37 & 97.63 \\
\hline Flupentixol & 200.0 & 4.08 & 4.08 & 4.69 & 104.70 & Zolpidem & 375.0 & 1.25 & 2.78 & -1.22 & 98.79 \\
\hline & 500.0 & 2.23 & 3.12 & -0.55 & 99.45 & & 1250 & 0.65 & 2.63 & -1.54 & 98.46 \\
\hline & 15.00 & 8.41 & 10.20 & -6.64 & 93.36 & & 25.00 & 6.25 & 6.40 & 1.90 & 101.90 \\
\hline Haloperidol & 40.00 & 2.72 & 6.06 & -1.02 & 98.98 & Zuclopenthixol & 200.0 & 2.82 & 3.20 & 4.85 & 104.80 \\
\hline & 150.0 & 6.25 & 6.25 & -4.09 & 95.91 & & 500.0 & 0.91 & 1.10 & -1.37 & 98.63 \\
\hline & 60.00 & 3.05 & 3.05 & -6.20 & 93.80 & & & & & & \\
\hline Imipramine & 300.0 & 2.04 & 3.15 & 1.33 & 101.30 & & & & & & \\
\hline & 600.0 & 2.67 & 3.23 & -0.51 & 99.49 & & & & & & \\
\hline
\end{tabular}

$\mathrm{A}=$ Precision, $\mathrm{A} 1=$ Repeatability $(\mathrm{RSD} \%), \mathrm{A} 2=$ Intermediate precision $(\mathrm{RSD} \%), \mathrm{B}=$ Trueness, $\mathrm{B} 1=$ Relative bias $(\%), \mathrm{B} 2=$ Recovery $(\%)$. 
Table 3. Results for limits of quantification and detection of the method against molecule therapeutic windows

\begin{tabular}{|c|c|c|c|}
\hline Molecules & $\begin{array}{l}\text { Therapeutic windows } \\
(\mathrm{ng} / \mathrm{mL})\end{array}$ & $\begin{array}{l}\text { LOD } \\
(\mathrm{ng} / \mathrm{mL})\end{array}$ & $\begin{array}{l}\text { LLOQ - ULOQ } \\
(\mathrm{ng} / \mathrm{mL})\end{array}$ \\
\hline Alprazolam & $10-50$ & 3.0 & $9-300$ \\
\hline Amitriptyline & $50-200$ & 4.8 & $16-600$ \\
\hline Bromazepam & $80-170$ & 2.3 & $8-1250$ \\
\hline Carbamazepine & $6000-12000$ & 20.5 & $68-50000$ \\
\hline Chlorpromazine & $30-300$ & 1.2 & $4-800$ \\
\hline Citalopram & $20-200$ & 3.5 & $11-1000$ \\
\hline Clomipramine & $100-250$ & 11.8 & $39-1000$ \\
\hline Clonazepam & $20-80$ & 3.8 & $13-400$ \\
\hline Diazepam & $125-1500$ & 6.2 & $20-3000$ \\
\hline Droperidol & $5-50$ & 1.8 & $5-500$ \\
\hline Fluoxetine & $100-450$ & 6.7 & $22-1500$ \\
\hline Flupentixol & $1-15$ & 3.6 & $12-500$ \\
\hline Haloperidol & $5-17$ & 2.9 & $10-150$ \\
\hline Imipramine & $45-250$ & 9.0 & $30-600$ \\
\hline Levomepromazine & $15-60$ & 3.6 & $12-400$ \\
\hline Lorazepam & $20-250$ & 2.0 & $6-800$ \\
\hline Midazolam & $80-250$ & 3.0 & $10-1500$ \\
\hline Nordiazepam & $200-1800$ & 5.0 & $16-2500$ \\
\hline Olanzapine & $20-80$ & 3.7 & $12-300$ \\
\hline Phenobarbital & $15000-40000$ & 437.0 & $1459-150000$ \\
\hline Phenytoin & $10000-20000$ & 21.0 & $70-50000$ \\
\hline Pipamperone & $100-400$ & 8.8 & $30-3000$ \\
\hline Risperidone & $20-60$ & 5.4 & $18-400$ \\
\hline Sulpiride & $200-1000$ & 11.0 & $37-4000$ \\
\hline Thiopental & $1000-5000$ & 3.5 & $12-12500$ \\
\hline Zolpidem & $80-300$ & 1.8 & $6-1250$ \\
\hline Zuclopenthixol & $4-50$ & 2.9 & $10-500$ \\
\hline
\end{tabular}



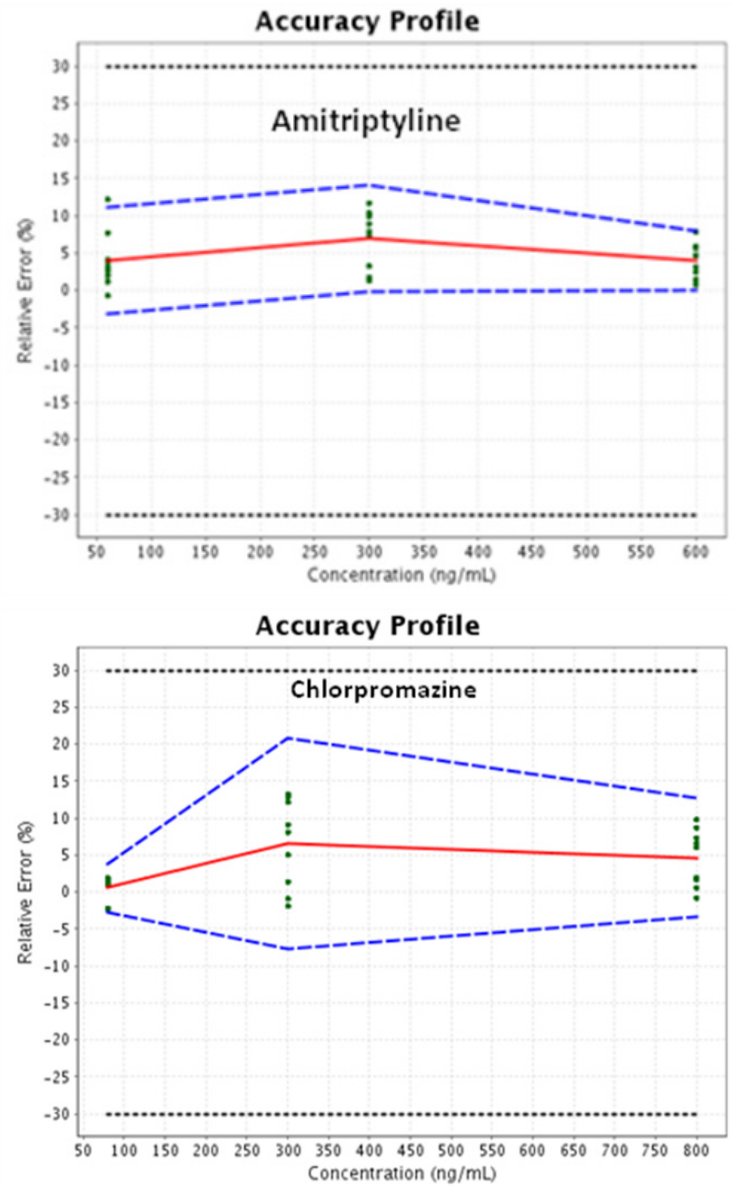
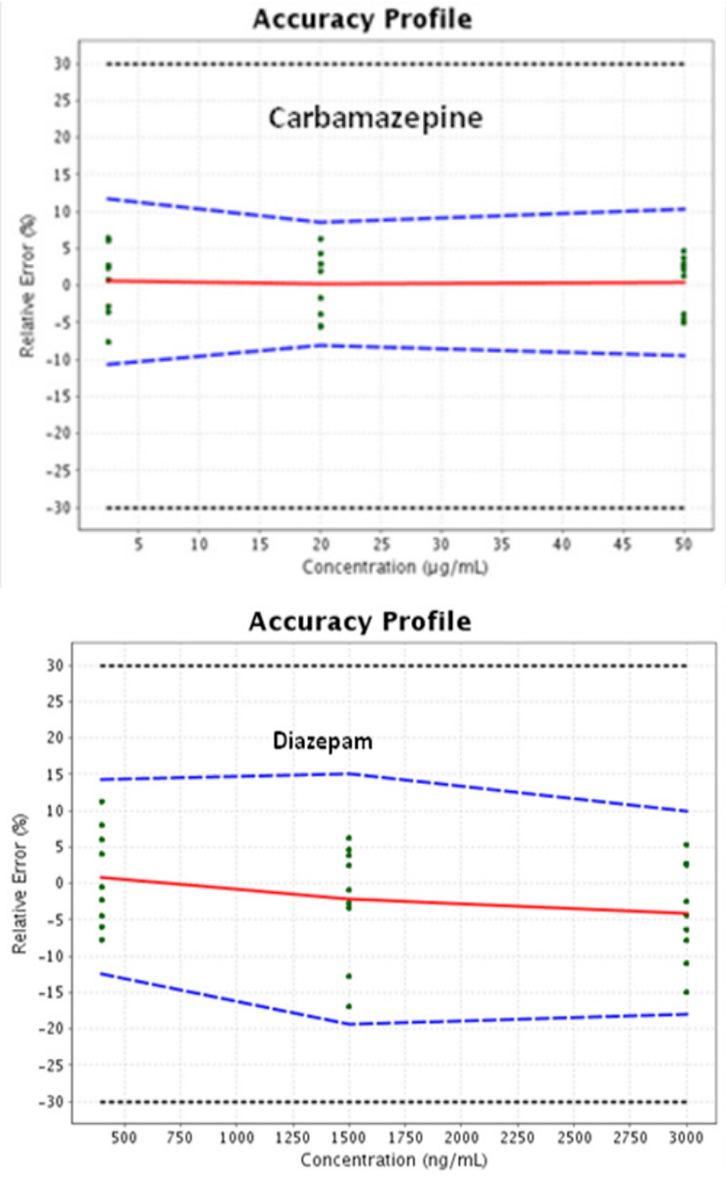

Figure 3. Accuracy profiles for 4 molecules taken as examples

The plain mid line stands for the relative bias, the dashed lines correspond to the $\beta$-expectation tolerance limits and the dotted lines represent the acceptance limits. The dots represent the relative error of the back-calculated concentrations and are plotted with respect to their targeted concentrations.

\section{Discussion}

According to various regulatory documents for validation of analytical methods including harmonized strategies for validation of quantitative analytical procedures, response function, linearity, selectivity, trueness, precision, accuracy and limits of quantification are validation parameters, commonly verified during the validation process (Hubert et al., 2007; Hubert et al., 2007 ). Requirements to be met have been set for a method to be valid. As far as precision is concerned, according to the FDA, among other requirements for a bioanalytical method to be considered as valid, the RSD \% should not exceed $15 \%$ except for LLOQ (Rozet et al., 2007; Hubert et al., 2007 a). When we consider both repeatability and intermediate precision for all molecules at all tested concentration levels, the maximum value of the relative standard deviation that we found was $13 \%$. . Despite differences in decision rules observed in various regulatory documents, the accuracy of the method remains so far the main criterion commonly used in deciding the validity of analytical procedures (Rozet et al., 2007; Hubert et al., 2008). According to the validation process used here, the method is considered as valid within the range where the accuracy profile is within acceptance limits. Therefore, the validity of the validated analytical procedure was demonstrated within tested dosing intervals for all molecules. As far as limits of quantification are concerned, both low and upper limits of therapeutic windows of all tested drugs were covered except for haloperidol, flupentixol and zuclopenthixol where the low limits were not covered.

\section{Conclusion}

Monitoring plasma concentration levels of psychotropic drugs remains a useful tool for the optimisation of treatment and confirmation of toxicity for these drugs. The aim of this study was to validate an analytical method that could be used in such activities for psychotropic drugs commonly prescribed in Rwanda. A simple and accurate HPLC method allowing simultaneous determination 
of several molecules and applicable in routine activities of clinical laboratories, has been successfully validated. Except for haloperidol, flupentixol and zuclopenthixol where it is only applicable for the confirmation of intoxication, the method is suitable for both therapeutic drug monitoring and confirmation of drug poisoning.

\section{Acknowledgment}

We gratefully acknowledge the financial support of the Belgian Technical Cooperation.

\section{Declaration of interest}

The authors report no declarations of interests.

\section{References}

Addington, D. (2009). Best practices: improving quality of care for patients with first-episode psychosis. Psychiatr Serv, 60, 1164-1166.

Adli, M., Baethge, C., Heinz, A., Langlitz, N. \& Bauer, M. (2005). Is dose escalation of antidepressants a rational strategy after a medium-dose treatment has failed? Eur Arch Psychiatry Clin Neurosci, 55, 387-400.

Arlenda Home Page, enoval Version V3.0a PROD, Last update: June 30, 2011. Accessed from https:/ /www.arlenda.com.

Bates, D.W. \& Gawande, A.A. (2003). Improving safety with information technology. N Engl J Med, 348, 2526-2534.

Baumann, P., Hiemke, C., Ulrich, S., Eckermann, G., Gaertern, I., Gerlach, M., Zernig, G. (2004). The AGNP-TDM expert group consensus guidelines: therapeutic drug monitoring in psychiatry. Pharmacopsychiatry, 37, 243-265.

Bengtsson, F. (2004). Therapeutic drug monitoring of psychotropic drugs. TDM "nouveau". Ther Drug Monit, 26, 145-151.

Brosen, K. (1996). Drug-metabolizing enzymes and therapeutic drug monitoring in psychiatry. Ther Drug Monit, 18, 39- 396.

Bugamelli, F.C., Sabbioni, R., Mandrioli, E., Kenndler, F., Albani, M.A. \& Raggi, M.A. (2002). Simultaneous analysis of six antiepileptic drugs and two selected metabolites in human plasma by liquid chromatography after solid-phase extraction. Anal.Chim. Acta, 472, 1-10.

Cutroneo, P., Beljean M., Tan Luu, P.R. \& Siouffi, A.M. (2006). Optimization of the separation of some psychotropic drugs and their respective metabolites by liquid chromatography. Journal of Pharmacentical and Biomedical Analysis 41, 333-340.

Hiemke, C. (2008). Clinical utility of drug measurement and pharmacokinetics therapeutic drug monitoring in psychiatry. Eur J Clin Pharmacol, 64, 159-166.

Hiemke, C. (2008). Therapeutic drug monitoring in neuropharmacology: does it hold its promises? Eur Arch Psychiatry Clin Neurosci, 258, (Suppl 1), 21-27.

Hiemke, C., Baumann, P., Bergemann, N., Conca, A., Dietmaier, O., Egberts, K., Zernig, G. (2011). AGNP Consensus Guidelines for Therapeutic Drug Monitoring in Psychiatry: Update 2011. Pharmacopsychiatry, 44, 195-235.
Hubert, P., Nguyen-Huu, J.J., Boulanger, B., Chapuzet, E., Cohen, N., Compagnon, P.A., Rozet E. (2007) Harmonization of strategies for validation of quantitative analytical procedures. A SFSTP proposal-Part III. Journal of Pharmacentical and Biomedical Analysis, 45, 82-96.

Hubert, P., Nguyen-Huu, J.J., Boulanger, B., Chapuzet, E., Cohen, N., Compagnon, P.A., Rozet, E.(2008) Harmonization of strategies for validation of quantitative analytical procedures. A SFSTP proposal-Part IV. Journal of Pharmacentical and Biomedical Analysis, 48, 760-771.

Hubert, P., Nguyen-Huu, J.J., Boulanger, B., Chapuzet. E., Chiap, P., Cohen, N., Rozet, E. (2007). Harmonization of strategies for validation of quantitative analytical procedures. A SFSTP proposal-Part II. Journal of pharmaceutical and Biomedical Analysis, 45, 70-81.

Jeffrey, A., Lieberman, J.A., Stroup, S.T., McEvoy, J.P., Swartz, M.S., Rosenheck, R.A., Hsiao J.K. (2005). Effectiveness of Antipsychotic Drugs in Patients with Chronic Schizophrenia. N Engl J Med, 353, 1209-1223.

Klotz, U. (2009). Pharmacokinetics and drug metabolism in the elderly. Drug Metabolism Reviews, 41 (2): 67-76.

Kratzsch, C., Peters, F.T., Kraemer, T., Weber, A. \& Maurer H. (2002). Screening, library-assisted identification and validated quantification of fifteen neuroleptics and three of their metabolites in plasma by liquid chromatography/ mass spectrometry with atmospheric pressure ionization. $J$. Mass Spectrum., 38, 283-295.

Malhotra, A.K., Murphy, G.M., Kennedy J.L. (2004). Pharmacogenetics of psychotropic drug response. Am. J. Psychiatry, 161, 780-796.

Müller, M. J., Dragicevic, A., Fric, M., Gaertner, I., Grasmäder, K., Härtter, S., ... Hiemke, C. (2003). Therapeutic drug monitoring of tricyclic antidepressants: how does it work under clinical conditions? Pharmacopsychiatry, 36, 98-104.

Preskorn, S.H. \&Fast, G.A. (1991). Therapeutic drug monitoring for antidepressants: efficacy, safety, and cost effectiveness . J Clin Psychiatry, 52 ( Suppl ), 23-33.

Raggi, M.A. (2002). Therapeutic drug monitoring: chemicalclinical correlations of atypical antipsychotic drugs. Curr. Med. Chem., 9, 1397-1409.

Rozet, E., Ceccato, A., Hubert, C., Ziemons, E., Oprean, R., Rudaz, S., Hubert, P. (2007). Analysis of recent pharmaceutical regulatory documents on analytical method validation. Journal of Chromatography A, 1158, 111-125.

Sanchez de la Torre, C., Martinez, M.A. \& Almarza, E. (2005). Determination of several psychiatric drugs in whole blood using capillary gas-liquid chromatography with

nitrogen phosphorus detection: comparison of two solid phase extraction procedures. Forensic Science International, 155, 193-204.

Sheng, J., Lei, J., Ju, H., Song, C. \& Zhang, D. (2010). Rapid ultraviolet monitoring of multiple psychotropic drugs with a renewable microfluidic device. Analytica Chimica Acta, 679: 1-6.

Smink, B.E., Brandsma, J.E., Dijkhuizen, A., Lusthof, K. J., Gier, J.J., Egberts, A.C.G. \& Uges, D.R.A. (2004). Quantitative analysis of 33 benzodiazepines, metabolites 
and benzodiazepine-like substances in whole blood by liquid chromatography-(tandem) mass spectrometry. Journal of Chromatography B, 811, 13-20.

Touw, D.J., Neef, C., Thomson, A.H. \& Vinks, A.A. (2005). Cost-effectiveness of therapeutic drug monitoring: a systematic review. Ther Drug Monit, 27, 10-17.

Trivedi, M.H., Rush, A.J., Bradley, N.G., Stewart J.W., Wisniewski S.R., Warden, D., Howland R. (2005). Maximizing the adequacy of medication treatment in controlled trials and clinical practice: STAR $(*) \mathrm{D}$ measurement-based care. Neuropsychopharmacol, 32, 2479-2489.

Vecchione, G., Casetta, B., Chiapparino, A., Bertolino, A., Tomaiuolo, M., Cappucci, F., Grandone E. (2012). A reliable and rapid tool for plasma quantification of 18 psychotropic drugs by ESI tandem mass spectrometry. Journal of Pharmaceutical and Biomedical Analysis, 67(68), 104- 113.
Wang, Q.L., Fan, L.Y., Zhang, W. \& Cao, C.X. (2006). Sensitive analysis of two barbiturates in human urine by capillary electrophoresis with sample stacking induced by moving reaction boundary. Anal. Chim. Acta, 580, 200-205.

Wilhelm, M., Battista, H.J. \& Obendorf, D. (2000). Selective and sensitive assay for the determination of benzodiazepines by high-performance liquid chromatography with simultaneous ultraviolet and reductive electrochemical detection at the hanging mercury drop electrode. J. Chromatogr. A, 897, 215225.

Zhang, J., Heineman, R. \& Halsall, H.B. (1999). Capillary electrochemical enzyme immunoassay (CEEI) for phenobarbital in serum. J. Pharmaceut. Biomed., 19, 145152. 